\title{
Dicotomía entre las orientaciones de la corte interamericana de derechos humanos y su aplicación en la normativa colombiana'
}

\author{
Dichotomy between the guidelines of the inter-american court of human rights and their \\ application in colombian Iaw
}

\author{
María Yarleidy Bedoya Macias ${ }^{2}$ - Esteban Garcés Naranjo ${ }^{3}$
}

\section{Resumen}

La Corte Interamericana de Derechos Humanos es un órgano judicial de la Organización de los Estados Americanos autónomo y cuyo propósito específico es aplicar e interpretar la Convención Americana de Derechos humanos o Pacto de San José de Costa Rica, instrumento internacional que fue incorporado a la legislación nacional con la ley 16 de 1972 para reducir o mitigar las diversas infracciones cometidas a los derechos humanos en los estados asociados a ellos. Por tanto, lo que se pretendió con esta investigación fue establecer las posibles irregularidades que pueden producirse en el ejercicio de la función disciplinaria respecto a los servidores públicos de elección popular, ya que existen varios desacuerdos en lo que respecta a las facultades y garantías procesales existentes en el desarrollo del proceso disciplinario.

En resumen, con este estudio se revisó si la Procuraduría General de la Nación, como autoridad administrativa disciplinaria, aplicó las disposiciones de control de convencionalidad y constitucionalidad en las decisiones proferidas contra miembros electos popularmente; y así establecer si esta entidad se encuentra autorizada para imponer sanciones que limiten el ejercicio de derechos políticos, de conformidad con lo dispuesto en los artículos 8, 23.1 y 23.2 de la referida Convención.

Palabras clave: control de convencionalidad, servidores públicos, elección popular, autoridades disciplinarias, sanción disciplinaria.

\section{Abstract}

The Inter-American Court of Human Rights is a judicial body, It belongs to the Organization of American States, which has autonomy and the specific purpose of applying and interpreting the United States Convention on Human Rights or covenant in San José, Costa Rica. In its legislation, Colombia has accepted this convention through the Constitutionality Block, in order to reduce or mitigate the various human rights violations committed in the states associated with them. Therefore, what led to this investigation was possible irregularities that may occur in the exercise of the disciplinary function, in relation to specific and specific cases of elected officials, Since there had been a number of disagreements on that point on the part of a number of public officials, it was due to the lack of procedural powers and guarantees during the course of the disciplinary process.

\footnotetext{
${ }^{1}$ Esta investigación tiene como propósito establecer el alcance de la orden dada por la Corte Interamericana de Derechos Humanos en sentencia del 8 de julio de 2020 respecto a la adecuación normativa que debe adelantar el Estado colombiano con relación a la capacidad de limitar los derechos políticos de los servidores públicos elegidos por voto popular.

${ }^{2}$ Abogado, actualmente realizando especialización en Derecho Administrativo en la corporación Universitaria Americana: Correo electrónico: bedoyamaria9395@americana.edu.co.
}

${ }^{3}$ Abogado, actualmente realizando especialización en Derecho Administrativo en la corporación Universitaria Americana: Correo electrónico: egarcesn@gmail.com 
In summary, this study reviewed whether the Office of the Attorney General of the Nation, as a disciplinary administrative authority, applied the provisions of control of conventionality and constitutionality in its decisions against elected popular members; and in the same way if authorized to impose sanctions in this regard, in accordance with the provisions of articles 8, 23.1 and 23.2 of the Convention.

Key Words: control of conventionality, public servants, popular election, disciplinary authorities, disciplinary sanction.

\section{Introducción}

En este estudio se revisaron los diferentes decisiones en las que ha evolucionado la Corte Interamericana de Derechos Humanos en torno al control de la convencionalidad y el control de la constitucionalidad con respecto a la ley colombiana, y tratando de resolver la teoría de que mantener dichos fenómenos legales, en aplicación a ellos, vincular la función que realiza la Procuraduría General de la Nación, como institución responsable del poder disciplinario del estado, cuyos poderes están establecidos en la constitución política de 1991, en sus Artículos 278 y 279, así como el artículo 25 de la Ley 734 de 2001; de los cuales es objeto de investigación las sanciones que se aplican a los funcionarios representantes electos que se encuentren en el ejercicio de sus funciones y, en algunos casos, incluso si se dan de baja del servicio.

La Procuraduría General de la Nación en aplicación de dicha facultad constitucional, que por norma legal se encuentra establecida, impone sanciones sin tener en cuenta las normas de carácter internacional que gobiernan de igual manera escenarios como los del objeto de estudio. Estas normas tienen como origen de aplicación el Bloque de Constitucionalidad por medio del cual se reconocen las normas de carácter internacional que ejercen soberanía sobre las normas nacionales y, en algunas ocasiones, sobre la misma Constitución, siendo un referente indispensable al momento de aplicar parámetros que permitan ejercer el control de constitucionalidad sobre las leyes, y del cual adicionalmente permite el surgimiento del Control de Convencionalidad, como una herramienta para dar una aplicación efectiva a ese bloque de constitucionalidad, así como un eficaz instrumento para el respeto y garantía efectiva de los derechos humanos, a través de un mecanismo internacional como lo es la Convención Americana de Derechos Humanos.

Por lo tanto, era necesario identificar el área de aplicación de las facultades disciplinarias del Ministerio Público en materia de: Sanción de cese e incapacidad para desempeñar funciones públicas en cargos de elecciones generales en el sistema legal colombiano contra el control Convencionalidad, por lo que para se desarrolló una revisión de los elementos legales de la figura, establecidos en el Sistema Interamericano de Derechos Humanos, para identificar declaraciones distintas a las identificadas en la jurisprudencia y así establecer la posición jurídica de la Corte Interamericana de derechos humanos en relación con las disposiciones de la Convención Americana Derechos Humanos (Pacto de San José) desde escenarios supra-nacionales. Estas decisiones abarcan muchas de las dimensiones contenidas en los tratados internacionales firmado por las partes miembros con instituciones y organizaciones internacionales dentro de la Organización de Estados Americanos, la Convención Interamericana para Prevenir y Sancionar la Tortura, y Convención Interamericana sobre Desaparición Forzada de Personas de Belém do Pará como fuente de derecho.

Como prueba de ello, se encontraron sentencias en el caso López VS Venezuela, Amonacid y otros VS Chile, que son de importante estudio porque a través de ellas la Corte Interamericana de Derechos Humanos declara y ratifica la obligación de los Estados parte de organizar todo el aparato gubernamental y, en general, todas las estructuras a través de las cuales se manifiesta el ejercicio del poder público, con el fin de asegurar legalmente el libre y pleno ejercicio de los derechos humanos para prevenir, investigar y castigar cualqui- 
er infracción de estos y más aún cuando sean reconocidos por la Convención. Es así como la Corte Interamericana pretende reafirmar la situación de diversos jueces y tribunales nacionales que, si bien están sujetos al estado de Derecho, como es el caso del Procuraduría General de la Nación, quienes a su vez están obligados a aplicar las disposiciones vigentes en el ordenamiento jurídico, deben tener en cuenta que cuando un Estado ha ratificado un tratado internacional como la Convención Americana sobre Derechos Humanos, como es el caso de Colombia, sus jueces también están sujetos a ella y, para aterrizar los postulados normativos relacionados con el tema anterior, se estudiaron las sentencias T -976 de 2014 y SU- 355 de 2015 de la Corte constitucional sobre el caso del señor Gustavo Petro Urrego y la sentencia SU-712 de 2013 respecto a la exsenadora Piedad Esneda Córdoba, a través de las cuales fue posible examinar la aplicación del Control de Convencionalidad y Constitucionalidad en Sanciones de Destitución e Inhabilidad de funcionarios de elección popular, evidenciando que, a pesar de que para el Estado colombiano la Convención Americana sobre Derechos Humanos tiene fuerza vinculante, no se considera aplicable en absoluto la normatividad del Sistema Interamericano de Derechos Humanos, en los casos ya indicados, en virtud de la disposición constitucional que otorga facultades disciplinarias en cabeza del Ministerio Público, a través de la Procuraduría General de la Nación.

\section{Metodología}

Se realizó la revisión de la normativa y posiciones adoptadas por las instituciones no solo de orden nacional, sino también de carácter internacional, lo que condujo a una mejor comprensión y conocimiento del tema de investigación, este método de interpretación de la problemática planteada es de orden jurídico y su desarrollo se abordó desde el nivel descriptivo.

El método deductivo tiene como objetivo cultivar y estudiar las diferentes sentencias de la Corte Interamericana de Derechos Humanos en control de convencionalidad y control de constitucionalidad desarrollado en nuestro derecho interno para disipar la teoría de mantener estos fenómenos legales al formar elementos generales del proceso investigativo.

\section{Desarrollo}

El presente trabajo nos permitió abordar la noción del control de convencionalidad, concepto novedoso que implica reconsiderar la pirámide normativa de nuestro sistema jurídico como una extensión del ya conocido bloque de constitucionalidad.

La decisión de la Corte Interamericana de Derechos Humanos introdujo a los órganos vinculados a la administración de justicia la obligación de verificar el cumplimiento de las convenciones suscritas por el Estado y la adecuación del ordenamiento jurídico vigentes a tales disposiciones; cuya interpretación no puede ser ajena al alcance dado por dicho organismo internacional; de tal manera que dicho control debe hacerse debe tener en cuenta el texto de la Convención y la jurisprudencia de su interprete.

Con cierta razón, algunas personas han encontrado que limitar la facultad disciplinaria de la Procuraduría General de la Nación significaría tolerar la corrupción y la garantizar la impunidad a sus autores, dada la incapacidad que ha tenido el aparato judicial, en cabeza de la Fiscalía General de la Nación, de sancionar penalmente aquellos escándalos ampliamente conocidos. De ello, resulta necesario evaluar la necesidad de adecuar la institucionalidad estatal para fortalecer la lucha contra la corrupción y, al mismo tiempo, proteger los derechos políticos en los términos del Pacto de San José.

La Convención Americana de Derechos Humanos, la cual se encuentra incorporada en 
el ordenamiento jurídico colombiano a través del a través del bloque de constitucionalidad, establece en el artículo 23 los derechos políticos de los ciudadanos; reservando al juez competente en un proceso penal la capacidad de limitarlos. A pesar de lo anterior, la Carta Política Colombiana establece que algunas autoridades administrativas cuentan con la facultad de suspender los derechos políticos de los ciudadanos; situación que ha sido analizada y validada por la Corte Constitucional. En el caso Petro Urrego VS. Colombia, estudiado y decidido mediante sentencia del 8 de julio de 2020, la Corte Interamericana de Derechos Humanos encontró que la arquitectura establecida en la constitución política de 1991 no se adecua a los mandatos establecidos en la convención de 1969 y ordenó realizar los ajustes necesarios para su adecuación.

La Organización de Estados Americanos O.E.A. suscribió en la llamada Carta de la Organización de los Estados Americanos en Bogotá en 1948 (reformada por el Protocolo de Buenos Aires en 1967, por el Protocolo de Cartagena de Indias en 1985, por el Protocolo de Washington en 1992, y por el Protocolo de Managua en 1993) los postulados mínimos para cumplir con su objetivo de salvaguardar los derechos esenciales.

En el marco de esta reunión de Estados Americanos se redactó la Convención Americana sobre Derechos Humanos (CADH), en la cual se declaró la obligatoriedad de ésta para los Estados que la han ratificado o se adhieran a la OEA, entrando en vigor el 18 de Julio de 1978. Para dar herramientas concretas a la Convención se estructuraron dos organismos: la Comisión Interamericana de Derechos Humanos, de ahora en adelante CIDH, creada en 1959 en el Art. 106 de la Carta de la Organización de los Estados Americanos e iniciando funciones en 1960, cuando el Consejo de la OEA aprobó sus estatutos y eligió sus primeros miembros; en el marco del séptimo periodo extraordinario de sesiones, la Asamblea General de la OEA, reunida el 22 de mayo de 1979, nombró el primer tribunal que le daría el nacimiento a la Corte Interamericana de Derechos Humanos.

En la evolución del Derecho Internacional, las sentencias de la Corte Interamericana de Derechos Humanos (CoIDH) han adquirido, basadas en diferentes teorías jurídicas, una gran relevancia para los Estados a los cuales se les puede aplicar estas decisiones y por las lógicas jurídicas de poder es que hoy los ciudadanos acuden, dada la impunidad en sus países de origen, a organismos internaciones que les permiten salvaguardar sus derechos colectivos o individuales. Colombia no ha sido ajena a esta problemática, especialmente frente al fenómeno de impunidad de las víctimas del Estado, como el caso de la Unión Patriótica.

Por otra parte, no podemos olvidar que el garantismo se ha convertido en un elemento fundamental para la materialización de la democracia y de los derechos humanos en el contexto internacional, con el objeto de promover la justiciabilidad de los derechos y la viabilidad de la democracia, dando paso a una estrecha relación entre Justicia constitucional y Justicia Internacional con estándares garantistas en los que el elemento central es la formación de sistemas jurídicos transnacionales, que institucionalizan la protección jurídica a través de tribunales internacionales y supranacionales, en los cuales se armonizan los estándares de protección de los derechos humanos y de la democracia en su fundamentación, interpretación, y, particularmente, su aplicación.

Así las cosas, resaltamos un caso en paralelo como el estudiado, el caso de Almonacid Arellanos y otros contra Chile, que constituye un verdadero hito en la jurisprudencia de la Corte Interamericana de Derechos Humanos dado que en ella se exponen dos elementos cruciales para el ejercicio y preponderancia del Derecho Internacional sobre la legislación interna, la primera es el Control de Convencionalidad y la segunda es la Interpretación Conforme. El Control de Convencionalidad surgió en pleno por la Corte Interamericana de Derechos Humanos en el análisis de este último caso, plasmado en el considerando 124, en donde manifiesta que el Poder Judicial debe ejercer un control de convencionalidad entre las normas jurídicas internas y la Convención Americana de Derechos Humanos, de 
tal manera que no se tenga en cuenta solamente el contenido del Tratado Internacional sino la interpretación que de él refiera la Corte Interamericana. (Caso Almonacid Arellanos y otros contra Chile, 2006).

Ahora bien, no se puede desconocer el impacto de la sentencia del 8 de julio de 2020 dada por la corte interamericana de derechos humanos en el caso concreto del señor Gustavo Petro Urrego, en dicha sentencia hace se consideró que el Estado violó los derechos políticos, así como la garantía de imparcialidad en relación con el principio de presunción de inocencia y el derecho a recurrir el fallo del señor Petro. Asimismo, determinó que se violó la garantía del plazo razonable y la protección judicial, así como el derecho a la igualdad ante la ley debido a que las acciones disciplinarias iniciadas en su contra tenían una motivación discriminatoria. ${ }^{1}$

Por otra partes, No se puede desconocer que la potestad disciplinaria, como señaló la Corte Constitucional, es una de las manifestaciones más importantes del estado del ius puniendi, que tiene como objetivo prevenir y sancionar conductas que vulneren el estricto cumplimiento de las obligaciones o impidan el buen desarrollo de las administración pública, desconociendo así los principios que rigen el desempeño de los cargos públicos, y por tanto esta competencia está indisolublemente ligada a la definición del Estado como Estado de Derecho.

En pronunciamiento posterior, sentencia SU-712 de 2013, la Corte Constitucional avaló nuevamente la compatibilidad de los poderes disciplinarios de la Procuraduría General de la Nación con el artículo 23 de la Convención Americana sobre Derechos Humanos. "la competencia atribuida constitucionalmente al Procurador General de la Nación para investigar y sancionar disciplinariamente a quienes desempeñen funciones públicas, inclusive tratándose de cargos de elección popular, es compatible con la Convención Americana sobre Derechos Humanos"2

Consecuentemente, en esta decisión, se consideró que del artículo 23.2 de la Convención Americana, "no se infiere una prohibición a los Estados para que en sus ordenamientos internos consagren otro tipo de restricciones a los derechos políticos, menos aun cuando emanan directamente de sus propias constituciones. En otras palabras, lo que hace el artículo 23 de la Convención es fijar una serie de pautas bajo las cuales el Legislador.

puede regular los derechos allí señalados, pero no establece una relación cerrada (numerus clausus) en cuanto a las eventuales restricciones que constitucionalmente pueden ser impuestas a su ejercicio."3

Finalmente, podemos afirmar, la evolución del Derecho Internacional, las sentencias de la Corte Interamericana de Derechos Humanos de ahora en adelante, han adquirido, basadas en diferentes teorías jurídicas, una gran relevancia para los Estados a los cuales se les puede aplicar estas decisiones y por las lógicas jurídicas de poder es que hoy los ciudadanos acuden, dada la impunidad en sus países de origen, a organismos internaciones que les permita la salvaguarda de sus derechos colectivos o individuales. Colombia no es la acepción a tan garante derecho buscando en un entorno el control de convencionalidad en el marco de las respectivas competencias y de las regulaciones procesales pertinentes, con lo que les otorga un margen de discrecionalidad judicial.

1 corte interamericana de derechos humanos caso Petro Urrego vs. Colombia sentencia de 8 de julio de 2020.

2 Sentencia SU-712 de 2013.

3 Ibídem 


\section{Conclusiones}

Se puede concluir que el Estado colombiano necesita una adecuación en las normas especiales para el legislador de acuerdo con el presupuesto, porque deben ser juzgados de acuerdo con una norma distinta a la Ley 734 de 2002, ya que las reglas, condiciones, procedimientos y sanciones no son las mismas ni es razonable en el ejercicio de los derechos políticos las sanciones que puede imponer la Procuraduría General y las consecuencias con el electorado; por tanto, se hace necesario establecer un proceso constitucional que garantice el respeto de los derechos de la minoría y la jerarquía institucional, incluida la dignidad parlamentaria.

El Estado colombiano, al firmar un tratado internacional, debe entender que su cumplimiento es de total obligatoriedad, al asumir el compromiso de cumplir con las disposiciones allí plasmadas, por lo que no es posible eludir su responsabilidad o compromisos respeto a la legislación nacional, los principios de precedencia constitucional o su autonomía estatal, dada la configuración del bloque de constitucionalidad de los tratados de derechos humanos.

\section{Bibliografía}

Caso Almonacid Arellanos y otros contra Chile, 12.057 (Corte Interamericana de Derechos Humanos 26 de septiembre de 2006).

Colombia, (1991) Constitución Política de Colombia, Bogotá, Legis.

Colombia (2002), Código Único Disciplinario, Bogotá, Temis.

Colombia, Corte Constitucional (2013, octubre), “Sentencia SU - 712", M. P. Palacio Palacio, J., Bogotá.

Colombia, Corte Constitucional (2018, abril), "Sentencia C -026/18”, M. P. Reyes Cuartas, J., Bogotá.

Colombia, senado de la república (29 junio de 2021), ley 2094, Bogotá.

Convención Americana, Derechos Humanos (22 de noviembre de 1969). Departamento de Derecho Internacional. OEA. Obtenido de http://www.oas.org/dil/esp/tratados_B32_ Convencion_Americana_sobre_Derechos_Humanos.htm. 